AOS - Amazônia, Organizações e Sustentabilidade

Amazon, Organizations and Sustainability.

v.9, n.2, ago./dez. 2020, p.11-31

DOI - http://dx.doi.org/10.17648/aos.v9i2.2324

ISSN on-line: $2238-8893$

\title{
PROGRAMA DE REDUÇÃO DA POBREZA RURAL NO PARÁ: UM OLHAR SOBRE A CONSTRUÇÃO DA GOVERNANÇA

\author{
RURAL POVERTY REDUCTION PROGRAM IN PARÁ: A VIEW OF \\ THE GOVERNANCE CONSTRUCTION
}

Brenda Cordovil Corrêa dos Santos ${ }^{1}$

Mário Miguel Amin Garcia Herreros ${ }^{2}$

\section{Resumo}

O formato construído para programas de redução da pobreza rural pressupõe uma interação entre financiadores (no caso em estudo, Banco Mundial), governos, comunidades locais e demais parceiros para o desenvolvimento de projetos. Em razão disso, estudar como a governança se reflete nos projetos é de fundamental importância. Esta pesquisa tem como objetivo analisar a governança nos projetos apoiados pelo Programa Pará Rural, nos municípios de Acará e Tracuateua, no Estado do Pará.Trata-se de uma pesquisa de natureza exploratória com abordagem qualitativa que se baseou em observação, pesquisa documental e aplicação de questionários semiestruturados. Como referencial teórico, foram utilizadas as teorias da governança, ação coletiva e a teoria institucional, com foco nos esquemas interpretativos e na construção da estratégia. A pesquisa analisou a governança e os padrões de articulação e cooperação, a forma como se dá a ação coletiva no desenvolvimento do projeto e como as instituições influenciam na formulação estratégica e, consequentemente, na governança das comunidades. Os resultados apontam que, quando o pensamento estratégico não se faz presente e a ação coletiva é frágil, as relações estabelecidas se configuram numa governança desfavorável ao sucesso dos empreendimentos. A pesquisa concluiu que a estratégia e a forma como ocorre a ação coletiva influenciam diretamente na governança.

Palavras-chave: Governança. Ação Coletiva. Estratégia. Banco Mundial. Desenvolvimento Rural.

\section{Abstract \\ The pattern built for rural poverty reduction programs supposes interaction between the sponsors (in this case, the World Bank), Government agents, local communities, and other partners for projects development. Thus, it is the significant importance to study how governance is reflected in projects. \\ 1 Mestrado em Administração pela Universidade da Amazônia. Professora na Universidade Federal Rural da Amazônia (UFRA). Belém, Pará, Brasil. E-mail: brendacordovil@ yahoo.com.br. \\ 2 Doutor em Agricultural Economics pela Universidade da Florida (USA). Professor do Programa de Pós-Graduação em Administração (PPAD) e em Desenvolvimento e Meio Ambiente Urbano da Universidade da Amazônia (UNAMA) e Professor do Programa de Mestrado em Gestão Pública do Núcleo de Altos Estudos Amazônicos da Universidade Federal do Pará. Belém, Pará, Brasil. E-mail: marioamin@ gmail.com.}


The research aims to analyze how has governance been carried out in projects supported by the Pará Rural Program in the municipalities of Acará and Tracuateua, in Pará State. It is a qualitative and exploratory research based on observation, documentary analysis and semi-structured interviews. Theoretically, the research takes the institutional theory and the theories of governance and collective action, particularly focusing on interpretive schemes and strategy building. The research analyzed the governance and its pattern of articulation and cooperation, the way of how collective action happens in projects formulation and consequently on the communities' governance. The research shows that when there are absence of strategic thinking and the collective action is fragile, the existing relations are unfavorable for governance and for the enterprise's success. The research concludes that the strategy and the way which the collective action happen has direct influence on governance.

Keywords: Governance. Collective Action. Strategy. World Bank. Rural Development.

\section{INTRODUÇÃO}

Ao longo do tempo, diversos significados foram atribuídos à palavra governança dando a ela um caráter diversificado, entretanto apesar das diferentes abordagens todos concordam que a governança tem como fundamento os relacionamentos e acordos estabelecidos. Esse entendimento remete imediatamente à gestão, pois é a partir da maneira como a gestão é exercida que serão construídos determinados tipos de relacionamentos, alianças e novas formas de exercício do poder.

Há diversos fatores a serem observados para a construção de uma governança que facilite o alcance de melhores resultados e seja positiva. Primordialmente, deve ser analisado o formato que ela adquire a partir dos elementos que a compõem. Dentre estes elementos, a gestão merece destaque, pois será ela quem determinará os caminhos e as alianças que serão estabelecidas. Assim, uma gestão eficaz entende a governança como resultado de elos fortes capazes de alavancar as iniciativas locais, gerando um conjunto de esforços positivos que contribuem de fato para o desenvolvimento. Neste contexto, a estrutura de governança refere-se a forma que a governança adquire a partir dos elementos que a compõem, resultados de sua interação com o meio e as instituições e sua adequação à realidade local de tal forma a garantir que seus objetivos sejam cumpridos.

Esta pesquisa analisou projetos financiados pelo Programa Pará Rural nos municípios de Acará e Tracuateua no estado do Pará, uma iniciativa do governo estadual, cofinanciada pelo Banco Mundial. Em se tratando da compreensão de projetos coletivos de apoio à agricultura familiar é importante destacar que envolvem fatores ligados a sua governança e a relação com os objetivos estratégicos e a ação coletiva das comunidades beneficiárias. Entende-se que o estudo da governança em projetos apoiados pelo Banco Mundial é de grande relevância por analisar as alianças constituídas e o papel delas no fortalecimento das atividades produtivas da agricultura familiar, favorecendo a geração de melhores resultados.

Com base nas influências do ambiente institucional, e fruto de processos cognitivos, emergem os esquemas interpretativos, gerando significados e interpretações partilhadas na organização e determinando diferentes cursos em face às pressões ambientais existentes (TAKAHASHI; MACHADO-DA-SILVA, 2002). O direcionamento dado determina a estratégia que a organização adotará e suas escolhas influenciam diretamente na governança e suas alianças estabelecidas de tal forma a atingir os objetivos. 
Em se tratando de projetos que visam à redução da pobreza rural, o estudo da governança adquire grande importância, já que o próprio entendimento do termo está associado ao debate políticodesenvolvimentista, no qual era utilizado para referir-se a políticas de desenvolvimento que se orientavam por determinados pressupostos sobre elementos estruturais como - gestão, responsabilidades, transparência e legalidade do setor público - considerados necessários ao desenvolvimento de todas as sociedades, especialmente por modelos pregados por organizações internacionais (KISSLER; HEIDEMANN, 2006).

Não se pode perder de vista o objetivo final dos projetos de redução da pobreza no campo que é a promoção do desenvolvimento rural. Para isso as estratégias de desenvolvimento rural devem ser estabelecidas de tal forma a potencializar a participação social e aprimorar a governança, construindo assim sólidos argumentos econômicos e políticos capazes de referendar o mundo rural como uma das opções da sociedade. Para que isto aconteça é preciso que haja um empenho em ampliar o debate entre os diferentes atores, sejam eles financiadores, órgãos públicos, pesquisadores e organizações rurais, unindo esforços em prol de fazer com que o desenvolvimento rural se configure em um processo de emancipação social para a agricultura familiar (NAVARRO, 2001).

Este artigo aborda aspectos da teoria da governança, da ação coletiva e institucional, com foco nos esquemas interpretativos e na construção da estratégica. $O$ estudo da governança analisa a capacidade de coordenação do Estado e está relacionada à integração de diferentes áreas do governo com a sociedade civil a fim de obter coerência e consistência nas políticas e na construção de novos formatos de relações envolvendo o governo local e a sociedade. A teoria institucional apoia a compreensão dos valores e crenças compartilhados que orientam as escolhas organizacionais e configuram os esquemas interpretativos que atuam como elementos mediadores na adoção de estratégias de ação (COCHIA; MACHADO-DA-SILVA, 2004).A pesquisa examina a forma como as estratégias se refletem nas alianças de governança estabelecidas.

Assim, objetiva-se neste artigo analisar a governança nos projetos de redução da pobreza rural co-financiados pelo Banco Mundial no Pará, nos municípios de Acará e Tracuateua, por viado exame dos padrões de articulação e cooperação que coordenam e regulam as parcerias nos projetos. Verifica-se de que forma ocorre a ação coletiva neles e como se dão as relações da comunidade com o ambiente, com foco no processo constitutivo das instituições e sua influência na formulação estratégica. Com o intuito de analisar como as partes se relacionam entre si e os acordos existentes entre elas, esta pesquisa questiona: como a governança se reflete no desenvolvimento dos projetos co-financiados pelo Banco Mundial para a redução da pobreza rural no Estado do Pará?

\section{REFERENCIAL TEÓRICO}

\subsection{Teoria Institucional, Esquemas Interpretativos e Estratégia}

A teoria institucional ganha espaço nos estudos organizacionais por fornecer maneiras de compreender padrões implícitos e a diversidade dentro das organizações, uma vez que os processos resultam não apenas da ação humana, mas igualmente das interações no contexto cultural e político. $\mathrm{O}$ institucionalismo aponta à necessidade de se levar em conta as mediações entre estruturas sociais e indivíduos e suas manifestações coletivas, ou ainda as mediações entre estruturas sociais e comportamentos individuais e a visualização das organizações como expressão de valores sociais (PEREIRA, 2012). 
Esta pesquisa analisa os elementos da teoria institucional e seus reflexos na concepção de esquemas interpretativos compartilhados nas organizações, os quais interferem diretamente na construção de sua estratégia. Entende-se que as relações de governança constituídas são frutos das escolhas estratégicas de cada organização, daí a importância dos elementos apresentados a seguir como teoria institucional, esquemas interpretativos e estratégia para a construção deste referencial teórico.

Compreendem-se instituições como o termo genérico que os economistas institucionalistas utilizam para representar o comportamento regular e padronizado das pessoas em uma sociedade, bem como as ideias e os valores associados a essas regularidades (BUENO, 2004). A partir da teoria institucional surge a noção de esquemas interpretativos como movimentos de adequação organizacionais, mediados pelas interpretações dos indivíduos e das próprias organizações. Entende-se por esquemas interpretativos o conjunto de ideias, valores e crenças que dá ordem e coerência às estruturas e sistemas em uma organização. Os esquemas interpretativos fornecem a visão de mundo, base da estratégia, e interferem na sua formulação através dos vieses cognitivos e são específicos para cada organização (MACHADO-DA-SILVA; FONSECA; FERNANDES 1999).

As interpretações e as ações apresentam como conseqüência uma manifestação material, que se configura no posicionamento estratégico da organização. A estratégia é vista como a maneira pela qual uma organização responde às demandas do ambiente, considerando as pressões exercidas por ele e a influência da cognição dos membros organizacionais, enquanto elemento norteador de sua definição. Este modelo considera o trinômio ambiente-interpretação-ação, em que os esquemas interpretativos daqueles que detêm o domínio da organização atuam como mediadores do posicionamento estratégico da empresa diante das pressões do contexto ambiental (MACHADO-DA-SILVA; FONSECA; FERNANDES 1999).

\subsection{Ação Coletiva}

Envolve as ações desenvolvidas para o alcance de objetivos comuns a mais de uma pessoa como fenômeno social, fruto da dicotomia dos interesses individuais e interesses coletivos. Para melhor compreensão a respeito do tema usa-se as abordagens de Hardin (1968) com "A tragédia dos Comuns", enfatizando a necessidade de controle (seja ela exercido pelo Estado ou pelo Mercado) para a manutenção de bens comuns. Ostrom (1990) afirma ser possível o uso de bens comuns desde que haja cooperação, reciprocidade, regras, sanções e comunicação e, por fim, Olson (1999) em a Lógica da Ação Coletiva estatui que o interesse comum dos membros de um grupo pela obtenção de um benefício coletivo nem sempre é suficiente para levar cada um deles a contribuir para a obtenção desse benefício.

Na década de 1960, Hardin publicou seu trabalho denominado "A tragédia dos Comuns”, onde realiza um exame crítico da relação homem e natureza, afirmando que os recursos comuns estariam condenados a um uso excessivo e a um esgotamento se não fosse realizada a sua privatização ou gestão pelo mercado de trocas. De acordo com Hardin (1968), quando um recurso natural renovável é utilizado por um coletivo, sem restrições na entrada, sem restrições no uso, e sem custos para os usuários, este recurso será sobre explorado, levando a Tragédia dos Comuns (SABOURIN, 2010; BALLESTEROS; ALCOFORADO, 2009).

Em contraponto às ideias de Hardin e baseada em uma análise crítica da Tragédia dos Comuns e da Teoria dos Jogos, Ostrom na década de 90 afirma que, para atender as situações de interdependência entre atores heterogêneos, a ação coletiva é implementada com o uso das instituições. A ação coletiva 
depende da capacidade de elaboração e adaptação de regras comuns, cuja existência dentro de um grupo constitui um estímulo à cooperação e compartilhamento. Os indivíduos obtêm resultados melhores construindo condições em que a reciprocidade, confiança e reputação contribuam para superar ou reduzir os interesses egoístas (SABOURIN, 2010; OSTROM, 1990).

Ainda sobre ação coletiva, a pesquisa sobre grupos de interesse havia ganho uma nova orientação após a publicação de "A Lógica da Ação Coletiva" por Olson em 1965 (republicado em português em 1999). O autor parte da premissa que a ação do grupo dependerá do que os indivíduos desse grupo fizerem e o que os indivíduos farão dependerá das vantagens relativas que lhes oferecerão o grupo. Alguns grupos adequadamente pequenos podem obter uma determinada quantidade de um benefício coletivo através de ação voluntária e racional, no entanto, quanto maior for o grupo, mais longe ele ficará de atingir o ponto ótimo de provimento do benefício coletivo. O autor ainda utiliza o termo carona (free-rider) para designar a atitude de indivíduos racionais e auto interessados que, mesmo considerando desejável a obtenção de um benefício coletivo, não se dispõem a colaborar para ela, pois esperam que outros indivíduos o façam (OLSON, 1999).

\subsection{Governança}

O debate sobre governança toma maior dimensão a partir das reflexões realizadas pelo Banco Mundial que visavam aprofundar o conhecimento das condições que garantem um Estado eficiente e a formas de exercício do poder. Ao longo do tempo, diversos significados foram atribuídos à palavra governança dando a ela um caráter diversificado, no entanto, sem perder de vista que engloba os relacionamentos e acordos estabelecidos dentro do sistema econômico, os quais vão além de mecanismos tradicionais de articulação, envolvendo também redes sociais informais e associações de diversos tipos.

O surgimento da expressão governança tem sua base nas reflexões do Banco Mundial que culminou na publicação do documento Governance and Development em 1992, que afirmava ser a governança o exercício de autoridade, controle, administração, e poder de governo e a maneira como este poder é exercido visando o desenvolvimento (GONÇALVES, 2005). O documento demonstra, com base em experiências do Banco Mundial com os programas e projetos que ajudou a financiar, que estes podem ser tecnicamente bons, mas podem não apresentar os resultados previstos por razões ligadas a qualidade da ação do governo.

Ao mencionar aspectos da má qualidade da ação governamental, o Banco Mundial destacou um sistema de controle fraco, políticas orçamentárias que não podem ser implantadas ou monitoradas, corrupção e incapacidade de envolver os beneficiários. Surge então o termo "boa governança" que envolve construir incentivos e desenvolver capacidades visando à criação e manutenção de um ambiente propício que favoreça o desenvolvimento. Engloba além da capacidade de gestão do setor público, o incentivo a formação de regras e instituições que forneçam um quadro previsível e transparente para a realização da gestão pública e privada garantindo a prestação de contas e um quadro jurídico favorável ao desenvolvimento (BANCO MUNDIAL, 1992).

No entanto o conceito de governança não se restringe aos aspectos gerenciais e administrativos do Estado, tampouco ao funcionamento eficaz do aparelho Estatal. Refere-se sim a padrões de articulação e cooperação entre atores sociais e políticos e arranjos institucionais que coordenam e regulam transações dentro e através das fronteiras do sistema econômico, incluindo-se não apenas os mecanismos tradicionais de agregação e articulação de interesses, tais como partidos políticos e grupos de pressão, como também redes sociais informais hierarquias e associações de diversos tipos (SANTOS, 1997). 
O valor da perspectiva da governança se assenta na sua capacidade de fornecer um quadro para compreender processos de mudança de governo. Refere-se ao desenvolvimento de novos estilos de governar onde as fronteiras entre o setor público e os setores privados tornam-se turvas e a essência da governança é o fato de se concentrar em mecanismos que não repousam sobre o recurso da autoridade e sanção do governo, mas sim como o resultado da interação de múltiplos atores (STOKER, 1998).

\section{O PROGRAMA PARÁ RURAL}

O Programa de Redução da Pobreza e Gestão dos Recursos Naturais do Pará (Pará Rural) foi desenhado pelo Governo do Estado do Pará focado em duas áreas críticas, consideradas prioridades para o Estado: a redução da pobreza rural e o melhoramento da gestão dos recursos naturais. O Pará Rural iniciou suas atividades no ano de 2007 e teve a finalização da primeira etapa no ano de 2015.

O Programa é uma proposta político-estratégica do Estado do Pará cofinanciada pelo Governo do Estado do Pará (GEP) e Banco Mundial (BIRD) que tem como área de abrangência geográfica o ambiente rural do Estado. Propôs-se a atuar em duas frentes convergentes de ação: a primeira, denominada Componente A, está relacionada ao aumento da renda e melhoria das condições de vida de comunidades rurais pobres mediante a implementação de projetos produtivos e provisão de infraestrutura complementar à produção. A segunda, chamada de Componente $\mathrm{B}$, está direcionada ao fortalecimento e aprimoramento do processo de gestão fundiária e ambiental do Estado, mediante investimentos na melhoria da estrutura institucional responsável pelo ordenamento territorial (PARA RURAL, 2014).

No que se refere ao componente A - investimento produtivo, objeto de análise deste trabalho, o Pará Rural visa o financiamento coletivo (para associações e cooperativas) para famílias de produtores rurais de bens e de serviços, dos quais, pelo menos, $70 \%$ com renda média familiar igual ou inferior a linha da pobreza (R \$ 5.580,00/ano, em 2007). Teve como meta o financiamento de aproximadamente 40 (quarenta) Projetos de Investimento Produtivo - (PIPs), que abrangeram os investimentos necessários ao fortalecimento das cadeias e/ou arranjos produtivos locais, por meio de ações que promoviam o planejamento, a organização e a comercialização da produção, incluindo a prestação de serviços de assistência e capacitação técnica aos produtores, além de pequenas obras de infraestrutura complementar, necessárias para apoiar a geração de renda (PARA RURAL, 2014).

Os projetos começaram como um empréstimo sem juros e com carência para início do pagamento e depois, por uma decisão do Governo do Estado em conjunto com o Banco Mundial, foram abonados, transformando o repasse a recursos a fundo perdido (não-reembolsável).

\section{METODOLOGIA}

A seguir será apresentado o método utilizado na pesquisa, os procedimentos para coleta de dados, os critérios para a seleção dos projetos estudados e a metodologia adotada para o mapeamento das relações, realizado com o intuito de compreender a governança nos projetos.

\subsection{Método}

Trata-se de uma pesquisa de natureza exploratória, com abordagem qualitativa. As pesquisas exploratórias têm como principal finalidade desenvolver, esclarecer e modificar conceitos e ideias, tendo em vista a formulação de problemas mais precisos ou hipóteses pesquisáveis para estudos 
posteriores. De todos os tipos de pesquisa, estas são as que apresentam menor rigidez no planejamento. Habitualmente envolvem levantamento bibliográfico e documental, entrevistas não padronizadas e estudos de caso (GIL, 1999; RAUPP; BEUREN, 2003).

Quanto aos aspectos operacionais da metodologia, foi realizada pesquisa documental já que os projetos de apoio à agricultura familiar têm as suas normas, objetivos e diretrizes registrados em Manuais Operacionais, Documento de Avaliação do Projeto - Apraissal (PAD) e "ajudas-memórias" de reunião realizadas com o Banco Mundial. Também foi realizado levantamento de dados primários junto às comunidades beneficiadas, sendo entrevistados presidentes das associações e associados que atuaram na gestão do empreendimento. Foram entrevistados também antigos funcionários do Programa Pará Rural e membros da prefeitura municipal, órgão do poder público mais próximo à representação local da comunidade.

Para a escolha das comunidades a serem estudadas nesta pesquisa foram adotados os seguintes critérios: localização geográfica, fase de execução do projeto, atividades produtivas, valores dos projetos e número de famílias. Com base nestes critérios foram selecionados: a Comunidade Menino Jesus, no município de Acará- PA e a Associação dos Criadores Orgânicos de Abelha de Tracuateua - APITRA, no município de Tracuateua-PA.

\subsection{Metodologia de Mapeamento das Relações}

Durante o levantamento de campo foram listados pelos representantes das comunidades as organizações ligadas ao Projeto, o motivo do relacionamento, o caráter (opcional ou obrigatório), o relacionamento esperado e o relacionamento ocorrido e, ao fim, uma avaliação do relacionamento com cada organização. Foram registradas somente as organizações listadas pela comunidade durante o levantamento, não sendo acrescidas a esta pesquisa aquelas não mencionadas, mesmo que, posteriormente, em outras fontes, fosse verificado algum tipo de relacionamento não citado.

Para análise do mapeamento das relações, elemento fundamental da governança, optou-se por dividir em quatro eixos as organizações com as quais as comunidades se relacionam, conforme a finalidade de cada organização. Foram definidos os seguintes grupos: Eixo 01 - Poder Público, composto por órgãos governamentais nas esferas municipal, estadual e federal; eixo 02 - Produção, que compreende as organizações relacionadas à produção, vendas, insumos e logística e eixo 03 Apoio técnico, que se refere às organizações relacionadas ao apoio da comunidade, tais como ONGs, Universidades, Sindicatos e Organizações ligadas as Sistema S, tais como Serviço Brasileiro de Apoio às Micro e Pequenas Empresas - SEBRAE, Serviço Nacional de Aprendizagem Rural -SENAR e Serviço Nacional de Aprendizagem Industrial - SENAI. O eixo 04 - Organizações privadas que se refere a empresas que se relacionam com a comunidade em assuntos que não ligados diretamente a produção, tais como compra e venda.

\section{RESULTADOS}

A seguir serão demonstrados os resultados da pesquisa com base nos levantamentos de campo realizados, conforme a metodologia descrita e o referencial teórico adotado. Serão apresentados os resultados por projeto, sendo primeiramente a Comunidade Menino Jesus no município de Acará-PA e a APITRA, em Tracuateua-PA. Em seguida será apresentada uma análise comparativa dos dois projetos. 


\subsection{Comunidade Menino Jesus - Acará}

A Comunidade Menino Jesus recebeu financiamento do Programa Pará Rural para a construção de uma casa de farinha mecanizada e uma unidade de beneficiamento de frutas para a venda de polpas congeladas. O projeto englobava incialmente 204 famílias quilombolas e o valor total do investimento é de aproximadamente R \$1.200.000,00 (um milhão e duzentos mil reais).

O projeto objetivou fortalecer o processo produtivo da mandioca e fruticultura, sendo financiada assistência técnica, capacitação, instalação de uma unidade de processamento de mandioca, (incluindo a construção civil, aquisição e instalação de máquinas e equipamentos e replantio de mandioca), instalação de uma unidade de processamento de fruta (incluindo a construção civil, aquisição e instalação de máquinas e equipamentos), material de consumo, aquisição de mudas e equipamentos para o manejo de açaí, adubo, preparo de terra e aquisição de caminhão.

\subsubsection{Trajetória Histórica da Governança}

A criação da Associação dos Moradores e Agricultores Remanescentes do Quilombo "Menino Jesus" se deu no ano de 1996. Em 2007, o primeiro projeto solicitando apoio para fortalecer a produção de mandioca foi encaminhado ao Programa Pará Rural. No entanto, somente em 2009, com o apoio da EMATER local, conseguiram que o projeto fosse analisado, sendo que o só foi assinado e realizada a primeira liberação financeira em 2013.

Embora criada em 1996, foi no ano de 2009 que o Instituto de Terras do Estado do ParáITERPA intensificou sua atuação junto à comunidade com vistas a emissão de títulos de terra, bem como a Secretaria de Meio Ambiente do Estado do Pará. Segundo informado, apesar das dificuldades encontradas em razão dos procedimentos burocráticos foram emitidas em tempo hábil as licenças necessárias para a execução do projeto.

Em 2012, a comunidade recebeu o apoio da prefeitura municipal com fornecimento de maquinário para preparo de área. Em 2014, a EMATER passou a trabalhar na emissão do Cadastro Ambiental Rural-CAR. Em 2015, a comunidade começou a se relacionar com a ADEPARÁ, visando o selo de produto da agricultura familiar; com a Casa Civil do Governo do Estado, através do Núcleo Quilombola, na busca de mais políticas públicas para este segmento e com a SESPA para capacitações, em especial, a de agente manipulador de alimentos.

Para melhor compreensão da trajetória histórica foram destacados os eventos que contribuíram para a construção da governança do projeto na Figura 1, sendo que os anos ou períodos não citados referem-se àqueles onde não houve relatos de eventos significativos associados ao projeto. A figura 01 resume a trajetória da governança na comunidade Menino Jesus 
Figura 01 - Trajetória da Governança - Comunidade Menino Jesus

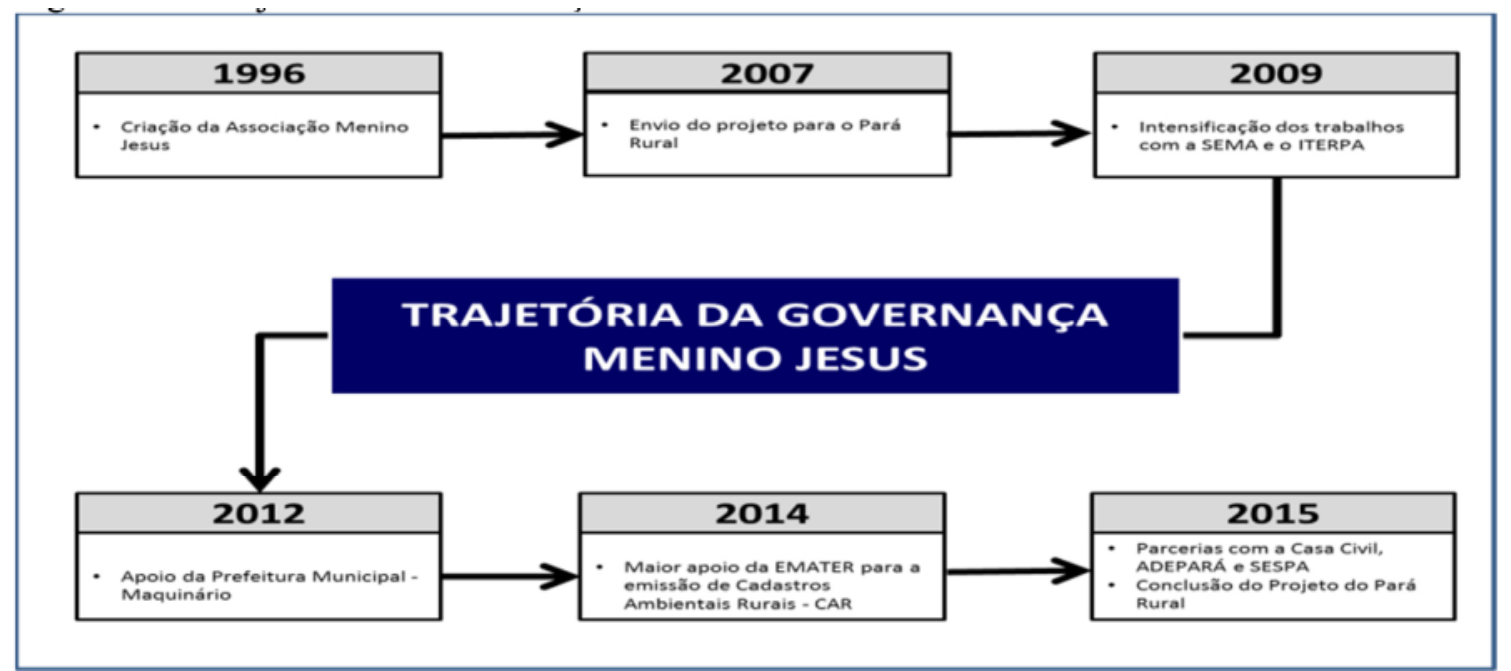

Fonte: Elaboração própria.

\subsubsection{A comunidade e a estratégia}

Os membros da comunidade antes do projeto tinham fornos artesanais individuais para o preparo da farinha de mandioca. Atualmente eles têm uma agroindústria com capacidade para o beneficiamento de 3.000 (três mil) quilos de mandioca. A mudança da realidade deve vir acompanhada de mudanças estratégicas e mudanças relacionadas à gestão do empreendimento. Vale destacar que a estratégia definida deverá se refletir na governança, já que os relacionamentos e alianças são motivados por objetivos afins. Para verificar os impactos na gestão e na estratégia da comunidade a partir da implantação do projeto do Pará Rural foram levantadas informações junto à comunidade.

Após a conclusão da agroindústria e para o seu funcionamento foram utilizados recursos oriundos de empréstimos dos associados e a pretensão atual é buscar financiamento para o capital de giro. A compra da mandioca é realizada com pagamento na hora e em localidades distantes da agroindústria o que onera ainda mais o seu preço. Em razão da dificuldade na compra da matériaprima o empreendimento não funciona com regularidade (diariamente em horário comercial), o que compromete a receita mensal.

Quando questionados a respeito de qual estratégia pretendiam adotar para à produção, foram descritos: baratear o custo, aumentar o prazo de pagamento da matéria-prima e investir em preparação de áreas dos cooperados para que pudessem fornecer a mandioca. Em se tratando de logística e comercialização, planejavam venda do produto na Central de Abastecimento do Estado (Ceasa), localizada na capital, e a venda em outros municípios, além de feiras e supermercados. Quanto a estratégias de parceria foi mencionada a Secretaria de Agricultura com o objetivo de obter sementes e auxílio no preparo de área e parcerias comerciais com supermercados. Por fim a estratégia ligada ao aprimoramento da gestão descrita por eles envolve a realização de cursos de gestão financeira e cooperativismo.

A descrição da estratégia por parte da comunidade é de fato reflexo do meio ao qual fazem parte. $\mathrm{O}$ anseio por preparação de área (presente ao descrever a estratégia de produção e de parcerias), por exemplo, reflete a forma vista por eles para se produzir mais e a falta de tecnologias mínimas de produção. No entanto dentre os itens custeados no projeto estavam horas de preparo de área, adubos, além de plantio de mandioca para que foram distribuídos para que a própria comunidade pudesse suprir a matéria-prima, porém, segundo informado, o plantio não deu certo por razões climáticas e ligadas ao desconhecimento de agricultores quanto às técnicas de plantio. Apesar de ter sido descrita a estratégia, 
não foram evidenciados meios claros para a sua realização. Os caminhos, por exemplo, para que um produto seja disponibilizado em supermercados envolve uma série de regularizações empresariais e sanitárias que necessitam aperfeiçoar parcerias existentes e estabelecer novas parcerias, no entanto não foi mencionado nada neste sentido.

A gestão do empreendimento é realizada ainda de maneira rudimentar, com base nos esquemas interpretativos construídos pela comunidade em consonância com uma realidade anterior de negócios muito mais caseira e artesanal. Nota-se a dificuldade de se estabelecer uma visão estratégica alinhada com a realidade atual da comunidade, hoje responsável por uma agroindústria com capacidade de produção de 3.000 (três mil) quilos de farinha de mandioca o que põe em risco a sobrevivência do negócio.

Além da agroindústria de beneficiamento de mandioca, foi entregue para a comunidade uma unidade de beneficiamento de frutas para a venda de polpas congeladas. O foco central é o açaí e uma parte dos recursos do projeto foi destinada para o manejo de 90 (noventa) hectares da fruta, no entanto, apesar de entregue,esta unidade ainda não está em operação por falta de materia-prima.Foi informado que em razão da demora na execução do projeto,a safra do açaí manejado não foi aproveitada para o beneficiamento nesta unidade.

\subsubsection{A ação coletiva envolvida no projeto}

O projeto inicialmente aprovado para a Comunidade Menino Jesus estabelecia um número de 204 (duzentos e quatro) famílias beneficiadas. Durante a realização da pesquisa foi informado que este número reduziu para 69 (sessenta e nove) famílias beneficiadas, sendo que apenas 05 (cinco) se envolvem ativamente da gestão do empreendimento. A comunidade atribui a diferença no número de famílias inicial e final à demora na implantação do projeto, já que, apesar da negociação com o Pará Rural ter iniciado no ano de 2006, apenas em 2013 foi realizada a primeira liberação financeira. Também foi informado que, de acordo com o Manual Operacional do Pará Rural, o limite financeiro dos projetos era estabelecido considerando o valor de US\$ 3.000,00 (Três mil dólares) por família, logo um maior número de famílias permitiria um maior valor global do projeto.

Ao analisarmos a diferença numérica da quantidade inicial e final dos beneficiários confirma-se a afirmação de Olson (1999) quanto ser mais fácil ocorrerem benefícios coletivos para grupos menores. Conforme relatos da comunidade, na elaboração do projeto foram informados os benefícios que todos teriam a partir com a sua execução, no entanto os custos desse benefício só começaram a ser percebidos com o passar do tempo, fato que pode ser responsável também pela redução na quantidade de beneficiários.

A agroindústria funciona no esquema de revezamento, onde as famílias organizam escalas de trabalho para a utilização da estrutura para a produção da farinha. Atualmente encontra-se em fase de debates a adoção de regras sanitárias e, apesar do debate para a elaboração das regras de uso comum da agroindústria estar em andamento, quando questionados sobre as sanções previstas no caso de descumprimentos das regras, foi informado que ainda não há nenhum tipo de sanção prevista. De acordo com Ostrom (1999) sanções são muito mais propensas a surgir a partir de um processo endógeno de elaborar as suas próprias regras, incluindo as sanções que devem ser impostas se essas regras são quebradas.

\subsubsection{Governança}

Para demonstrar a governança do projeto, foi mapeado em reuniões na comunidade: as organizações com as quais se relacionam, o tipo de relacionamento, tempo, nível de confiança, os 
resultados esperados e ocorridos e qual avaliação. $\mathrm{O}$ objetivo era identificar como as partes se relacionam entre si e os acordos existentes entre elas.

No mapeamento das relações foram listadas pela comunidade 15 (quinze) organizações com os quais eles se relacionam, sendo destas 10 (dez) ligadas ao eixo 01 - poder público, 02 (duas) ao eixo 02produção e 03 (três) ligadas ao eixo 03 - apoio técnico e nenhuma no eixo 04- organizações privadas.

Eixo 01 - poder público: No que se refere às organizações ligadas ao poder público foi destacado o papel do Programa Pará Rural (NGPR),Núcleo Quilombola da Casa Civil, Secretaria de Agricultura do Município (SAGRI - PM), Secretaria de Meio Ambiente do Governo do Estado (SEMA), Instituto de Terras do Governo do Estado do Pará - ITERPA, Agência de Defesa Agropecuária do Estado do Pará (ADEPARÁ), Empresa de Assistência Técnica e Extensão Rural do Governo do Pará (EMATER), Secretaria de Saúde do Governo do Pará (SESPA), um vereador representante da Câmara Municipal, Companhia Nacional de Abastecimento do Governo Federal- CONAB.

Eixo 02 - produção: Durante as reuniões foram listados dois compradores fixos para a farinha de mandioca produzida na comunidade Menino Jesus. Nas entrevistas foi relatado que a agroindústria havia iniciado suas atividades há apenas três meses e o principal problema enfrentado era a falta de materia-prima (mandioca) para a produção da farinha, já que o abastecimento de mandioca utilizando a roça dos cooperados ligados ao projeto não era suficiente para garantir o funcionamento da unidade de processamento.

Eixo 03 - apoio técnico: Neste eixo foram mencionados os relacionamentos com o Sindicato dos Trabalhadores Rurais, sendo avaliado como ótimo e com alto nível e confiança e com o Serviço Nacional de Aprendizagem Rural - SENAR e a empresa responsável pela assisntência técnica do projeto. Foi destacado o papel do Sindicato na orientação e apoio a comunidades, esclarecendo possíveis dúvidas e apoiando as ações realizadas e as capacitações realizadas pelo SENAR e a empresa responsável pela assistência técnico do projeto.

\subsection{APITRA -Tracuateua}

O projeto teve como principal objetivo fortalecer a apicultura, viabilizando o aperfeiçoamento da atividade em Tracuateua. Assim, visava apoiar a produção local de mel, além da construção de um viveiro de mudas para trabalhar com mudas fruteiras e de essências florestais, auxiliando a polinização e, também, para a venda de mudas e sementes. Inicialmente, 157 famílias faziam parte do projeto e o valor previsto era de aproximadamente $\mathrm{R} \$$ 1.200.000,00 (um milhão e duzentos mil reais).

O Pará Rural financiou para a Associação dos Criadores Orgânicos de Abelha de Tracuateua APITRA a construção do entreposto de mel, a aquisição de máquinas, equipamentos e utensílios (EPIS e melgueiras), aquisição de enxames, aquisição de um caminhão e um veículo tipo furgão, além da aquisição de mudas, capacitação e assistência técnica.

\subsubsection{Trajetória Histórica da Governança}

A ideia de trabalhar a apicultura no município iniciou-se no ano de 2008 quando um grupo de moradores de Tracuateua decidiu desenvolver um trabalho social junto à paróquia local, elaborando o projeto denominado "Sementes em Terra Boa". Para isso buscaram parcerias com instituições ligadas ao Sistema "S" visando capacitar os produtores locais. Ao entrar em contato com o Serviço Brasileiro de Apoio às Micro e Pequena Empresa (SEBRAE -PA) tomaram conhecimento do Projeto APIS (voltado para o fortalecimento da cadeia produtiva da apicultura), especialmente no estado do Piauí, uma iniciativa do SEBRAE-PI voltada para o incentivo da cadeia produtiva do mel. 
Os produtores de Tracuateua interessados em trabalhar com a apicultura realizaram uma visita ao estado do Piauí e após constatarem os resultados positivos da atividade solicitaram ao SENAR cursos voltados a atividade apícola e foram contemplados. No mesmo ano, os produtores tiveram também a oportunidade de participar de um evento voltado a agricultura familiar no Centro de Convenções de Belém - Hangar, aumentando ainda mais o conhecimento deles sobre o tema. Assim, ainda no ano de 2008, foi fundada a Associação dos Criadores Orgânicos de Abelha de Tracuateua - APITRA.

No ano seguinte, os associados obtiveram financiamentos do Programa Nacional para a Agricultura Familiar - PRONAF e adquiriram os primeiros kits de produtos apícolas. Também foi em 2010 que a associação deu entrada no Pará Rural do Projeto de financiamento para a atividade apícola e paralelamente se iniciou a parceria com o SESI para capacitação local que dura até os dias atuais.

No ano de 2011 o projeto foi aprovado pelo Pará Rural e, a partir daí, os associados tentaram se antecipar e começaram a estabelecer possíveis parcerias de vendas. Nesse sentido, procuraram uma das principais redes de supermercado da capital e fizeram uma apresentação do que era o projeto visando garantir futuros compradores. No ano seguinte, procuraram o Ministério da Agricultura Pecuária e Abastecimento visando apoio técnico.

Já que o projeto previa também a implantação de um viveiro de mudas, no ano de 2014 estabeleceram contato com uma grande fábrica nacional de cosméticos para garantir a possível venda das sementes produzidas no viveiro. Em 2015, soma-se à associação o apoio da Embrapa com um projeto de plantio de diversas variedades de mandioca com o objetivo de produzir maniva, fécula, farinha e etanol da mandioca e do Ministério de Desenvolvimento Agrário, por meio do cadastro da Associação no Programa Mais Gestão. A inauguração do empreendimento foi prevista para maio de 2016, já tendo sido adquiridos todos os equipamentos.

A figura 02 demonstra resumidamente a trajetória da governança da APITRA, em que foram destacados os eventos que contribuíram para a construção da governança do projeto, sendo que os anos não citados dizem respeito àqueles onde não houve relatos de eventos significativos associados ao projeto.

Figura 02 - Trajetória da Governança - APITRA

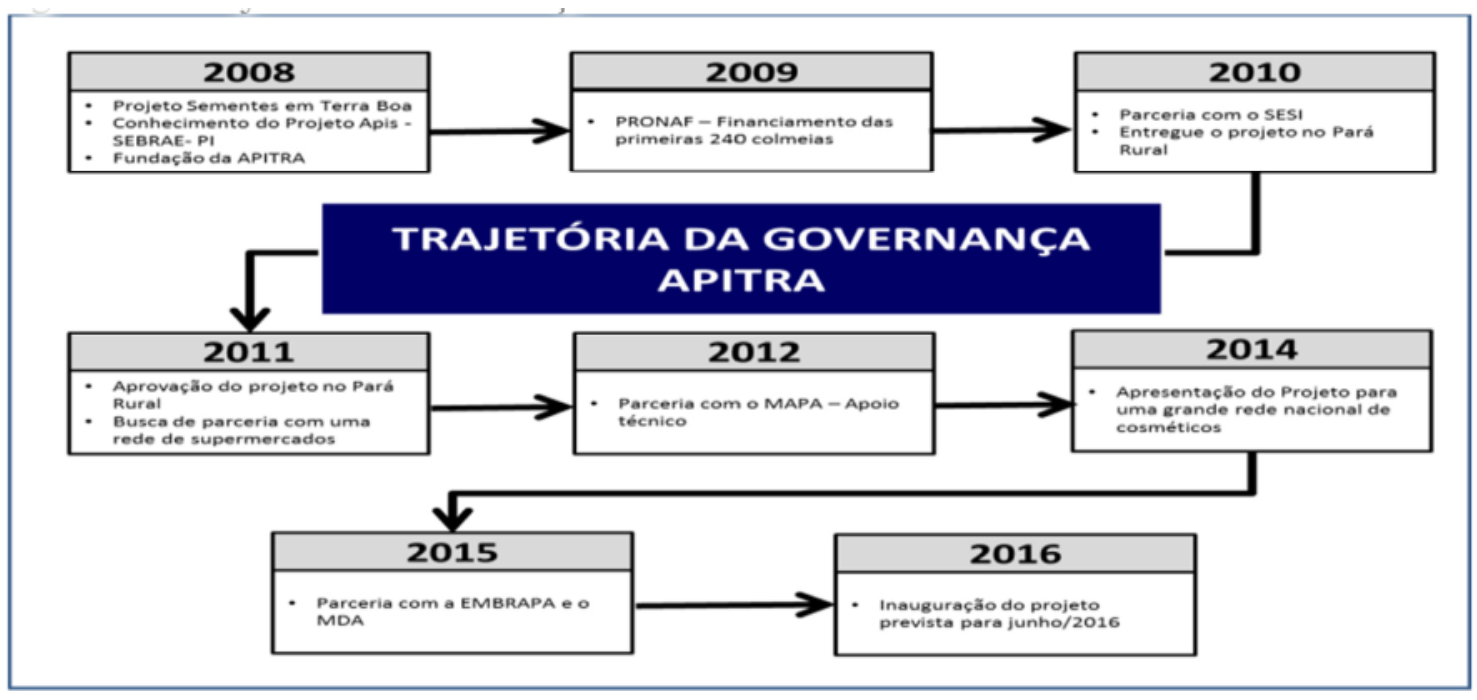

Fonte: Elaboração própria. 


\subsubsection{A comunidade e a estratégia}

Quando o Pará Rural aprovou o projeto encaminhado e começou a atuar no município, já havia um grupo capacitado na apicultura que deu início às suas atividades com recursos do Programa Nacional de Fortalecimento da Agricultura Familiar (PRONAF). Atualmente, a Associação conta com 2000 (duas mil) colmeias e produziu artesanalmente em 2015 um montante de $9.700 \mathrm{~kg} /$ ano de mel. Estima-se que após a conclusão do projeto a produção atinja o patamar de 80.000 kg/ano, em 2016 .

Os beneficiários do projeto atuam há 08 (oito) anos com a apicultura e quando questionados sobre o diferencial da APITRA, eles destacaram a mão-de-obra qualificada como principal diferencial, o que se reflete na trajetória histórica da Associação, marcada por cursos e intercâmbios de experiências (especialmente com o Piauí) e no perfil do seu dirigente. Este preocupado em construir o que ele chamou de "núcleo de conhecimento da associação" através do constante incentivo a qualificações dos seus membros e na preocupação com que, pelo menos, alguns associados façam cursos superiores, sendo o próprio presidente formado em dois cursos de graduação e estudante de mestrado.

Também destaca como diferencial os cuidados com a qualidade do produto, o que inclui o manejo do mel e o fato de não utilizar fumaça (fumígeno). A preocupação com a qualidade se reflete igualmente na busca por uma adequada disposição e layout do entreposto, em conformidade com a legislação vigente. Para tal, a Associação estabeleceu parceria com o Ministério da Agricultura, Pecuária e Abastecimento - MAPA que os apoia, analisando as plantas baixas, já tendo sido inclusive realizadas mudanças na estrutura civil da construção do entreposto para melhor atendimento de condições sanitárias e legais. Destaca-se a preocupação que tais ajustes sejam vistos e realizados anteriormente a conclusão da obra, já que após a estrutura física pronta torna-se muito mais complicado qualquer tipo de ajuste.

Quando questionados sobre a estratégia de produção, foi mencionada a intenção de pagar melhores preços para a aquisição de matéria-prima para os próprios associados, garantindo a regularidade de mel no entreposto e, consequentemente, beneficiando os seus associados com a compra de seu produto por preços justos. A diversificação da produção é tida como uma das principais estratégias da APITRA, já que quando questionados sobre a estratégia de comercialização foram bastante enfáticos ao afirmar que o objetivo é chegar a prateleiras de supermercados e farmácias do Pará e, para tal, precisam oferecer produtos semelhantes aos que são atualmente oferecidos nestes empreendimentos.

No que se refere à estratégia para parcerias, foi relatada que a prioridade é a busca de alianças com a iniciativa privada visando estabelecer acordos para a venda dos produtos da APITRA e o foco são donos de supermercados. O presidente da associação ressaltou que a iniciativa privada é fundamental para a sustentabilidade, com o mercado por meio dos empresários sendo um grande "termômetro de qualidade", pois as suas ações refletirão o status do produto e da gestão da associação. Quanto à estratégia para a administração, foi descrito o foco na capacitação do pessoal local, estratégia em execução, pois já existem pessoas se capacitando.

No caso da APITRA, ao analisar a trajetória da associação, é possível verificar claramente a consolidação dos sistemas interpretativos. O início da associação é resultado de uma observância da atividade apícola, seus benefícios, entraves e resultados em outros projetos. A interpretação é refletida na percepção compartilhada da apicultura como atividade com alto potencial gerador de renda para os beneficiários e a aprendizagem é traduzida através das ações de intercâmbio de experiência, capacitação e captação de recursos (através de PRONAF e Pará Rural, entre outros) para a consolidação da atividade no município. 


\subsubsection{A ação coletiva envolvida no projeto}

Segundo relatado pelo presidente da APITRA, a associação iniciou suas atividades com 157 (cento e cinquenta e sete) membros. A maior parte destes tinha relações de parentesco divididas em diferentes núcleos familiares, sendo composto por, por exemplo, pais, filhos e sobrinhos da mesma unidade familiar, todos vinculados a associação. À medida que as ações do projeto foram enfrentando dificuldades e os prazos para a conclusão final do entreposto foram sendo adiados, este número foi se reduzindo, sendo que atualmente conta com 57 (cinquenta e sete) associados, porém ainda em sua maioria com vínculos familiares.

Ao tratar do caráter onipresente e inevitável da filiação grupal, Olson (1999) tenta explicar as associações e afiliações a grupos na atualidade como um aspecto da evolução das sociedades industriais modernas de hoje a partir das sociedades primitivas precedentes. $\mathrm{O}$ autor parte do fato que grupos "primários" como a família e grupos de parentesco em geral, predominam nas sociedades primitivas respondendo por toda ou quase toda forma de interação humana e à medida que a sociedade se desenvolve ocorre uma diferenciação estrutural: novas associações emergem para assumir algumas das funções que anteriormente ficavam a cargo da família.

$\mathrm{Na}$ APITRA, mesmo antes do projeto ter sido integralmente concluído, já haviam sido estabelecidas regras de uso para alguns bens já entregue, como o caminhão e o veículo utilitário, consolidadas em um regime interno, no entanto não foram previstas sanções no caso do descumprimento. As regras foram construídas com o apoio do profissional agrônomo disponibilizado pelo Pará Rural para acompanhar as ações do projeto. O Conselho Gestor formado pelos membros da associação se reúne regularmente para discutir as regras que nortearão o entreposto quando concluído, estas regras serão consolidadas no regimento interno.

\subsubsection{Governança}

O objetivo do mapeamento das relações é identificar como as partes se relacionam entre si e os acordos existentes entre elas, demonstrando assim as alianças que compõem a governança. Para tal mapeamento, foi realizada reunião visando levantar as organizações que se relacionam com a APITRA e como são estes relacionamentos. Foram listadas pela associação 14 (quatorze) organizações com os quais eles se relacionam, sendo destas 06 (seis) ligadas ao eixo 01 - poder público, 03 (três) ao eixo 02- Produção e 05 (cinco) ligadas ao eixo 03 - apoio técnico e nenhuma no eixo 04 - empresas privadas.

Eixo 01 - poder público: No que se refere ao eixo 01, foi destacado inicialmente o Pará Rural, cujo objetivo era o financiamento do projeto, sendo avaliado como bom e com alto nível de confiança. O tempo do relacionamento de 05 (cinco) anos foi citado como longo, sendo destacado que se esperava um tempo mais curto para a execução. Também foi listada a Empresa de Assistência Técnica e Extensão Rural do Estado do Pará - EMATER, que atua junto a associação a 08 (oito) anos atendendo as expectativas dos associados, sendo avaliado como bom e nível de confiança alto.

Relacionados ao Governo Federal, atua junto à comunidade a Empresa Brasileira de Pesquisa Agropecuária - Embrapa, o Ministério da Agricultura, Pecuária e Abastecimento - MAPA e o Ministério do Desenvolvimento Agrário - MDA. A Embrapa tem em Tracuateua um projeto de pesquisa relacionado a mandioca em funcionamento a um ano com a APITRA, já que a associação também tem o interesse que os seus associados diversifiquem as suas atividades produtivas. O MAPA apoia a associação a 4 (quatro) anos com orientações técnicas visando a futura certificação do mel, analisando inclusive, anteriormente a construção civil, as plantas do entreposto e solicitando ajustes quando necessário, 
sendo avaliando como bom relacionamento. O motivo do relacionamento com o MDA é a adesão a 04 (quatro) meses ao Programa "Mais Gestão" que promove o fortalecimento de cooperativas da agricultura familiar, por meio da qualificação de seus sistemas de gestão (organização, produção e comercialização), a avaliação foi boa, porém foi destacado que ainda estão na fase inicial do programa.

Também foi listada a Prefeitura Municipal de Tracuateua, com quem a associação tenta se relacionar há três anos na busca por mais apoio técnico ao projeto e fornecimento de mel para a merenda escolar. No entanto, a avaliação foi ruim e o nível de confiança baixo, já que os objetivos do relacionamento não foram atingidos.

Eixo 02 - produção: $\mathrm{O}$ eixo 02 apresentou 03 (três) organizações com as quais a associação se relaciona. Vale destacar que em razão do entreposto ainda não estar concluído, os associados vendem individualmente toda a sua produção para uma empresa (aqui denominada de comprador 1), a qual vende produtos alimentícios a base de mel e seus derivados, incluindo xaropes e composto para fins medicinais enriquecidos com ervas, comercializando seus produtos para as principais redes de supermercado e farmácia do estado. Dentre as três organizações listadas, duas são os chamados futuros compradores, ou seja, potenciais compradores já contatados visando a venda dos produtos que serão feitos pela associação após a conclusão do entreposto.

A empresa que vamos denominar futuro comprador 1, faz parte de uma grande rede de supermercados o que demonstra um alinhamento com a estratégia descrita pelo presidente da associação, que objetiva disponibilizar o produto nas prateleiras de supermercados e farmácias. Já o futuro comprador 2 é uma empresa do segmento de cosméticos interessada na semente do ucuuba que será produzida no viveiro de mudas, parte integrante do projeto financiado pelo Pará Rural.

Eixo 03 - apoio técnico: No eixo 03 foram listadas 05 (cinco) organizações. Ligados ao sistema $\mathrm{S}$ (nome pelo qual ficou convencionado de se chamar ao conjunto de onze instituições de interesse de categorias profissionais, estabelecidas pela Constituição brasileira) estão presentes o Serviço Social da Indústria-SESI e o Serviço Brasileiro de Apoio às Micro e Pequenas Empresas - SEBRAE do Estado do Piauí. O SESI tem uma parceria há 06 anos no município de Tracuateua com a disponibilização de turmas regulares de ensino e o Sebrae do Estado do Piauí há oito anos, já que os contatos iniciais com a apicultura se deram através do projeto APIS no Piauí.

O Sindicato dos Trabalhadores Rurais do município apoia os produtores há oito anos, demonstrando um bom relacionamento com eles. Ainda em consonância com o eixo 03, os membros da associação também procuraram a Organização das Cooperativas do Brasil (OCB) há dois anos, visando apoio na transição de uma associação (situação atual) para uma cooperativa (constituição legal que almejam). A Igreja católica foi considerada determinante, já que a partir do projeto da paróquia "Sementes em Terra Boa", em 2008, que foram iniciadas as parceiras e a criação da associação. No eixo 04 (organizações privadas, sem vínculo com a produção) nenhuma empresa foi citada.

\subsection{Análises Comparativas dos Projetos}

A seguir serão apresentados os principais pontos observados nos projetos estudados (Comunidade Menino Jesus e APITRA), considerando a trajetória histórica da governança, a estratégia, a ação coletiva e a governança.

\subsubsection{Trajetória Histórica da Governança}

A partir do relato da trajetória dos projetos é possível compreender como a governança foi construída 
ao longo da história de cada associação, o caminho trilhado na construção de alianças e, especialmente, o motivo pelo qual as parcerias foram estabelecidas. Com base nessa trajetória é demonstrado como a governança é moldada de acordo com a realidade de cada ambiente e suas especificidades.

Ao tratar de projetos na Amazônia e considerando a sua trajetória de desenvolvimento, Justen et. al. (2014) afirmam que se criam cenários propícios à constituição de sistemas produtivos locais, originados pela percepção dos agentes inseridos neste contexto em função da sua realidade e da sua vivência. Assim, surgem formas de organizações resultantes de articulação e interação entre agentes, que objetivam pela inserção das populações locais no cenário econômico, bem como por práticas e atividades de acordo com as características da região e o seu potencial para desenvolver-se.

\subsubsection{A comunidade e a estratégia}

Para que uma organização defina o caminho que ela deverá seguir, primeiramente, ela necessita compreender a sua realidade atual e a realidade posterior a implantação do projeto. É neste momento que transparecerá a visão de esquemas interpretativos, ou seja, o conjunto de ideias, valores e crenças que dá ordem e coerência às estruturas e sistemas em uma organização. São os esquemas que determinam o modo de perceber e sentir os problemas e possuem um papel fundamental no delineamento da estratégia: fornecer a visão de mundo e interferir na formulação estratégica através dos vieses cognitivos (MACHADO-DA-SILVA; FONSECA, 1999).

Quando questionados a respeito da estratégia da associação, a Comunidade Menino Jesus relatou uma percepção da realidade muito próxima da situação anterior do projeto, onde a infraestrutura de produção e a dimensão da atividade agrícola era significativamente inferior àquela obtida após os recursos do Pará Rural. Ao descrever o que almejavam e as ações futuras, o caminho de realização não foi explicitado de forma clara demonstrando que os esquemas interpretativos não se alinharam a nova realidade organizacional que, por comportar uma nova estrutura de maior porte e coletiva, traz consigo aumentos de custos inerentes à manutenção da nova realidade do negócio.

No caso da APITRA, o projeto do Pará Rural veio como resultado de uma estratégia construída para a implementação da atividade apícola planejada, incialmente a partir do conhecimento técnico daquela atividade, oriundo de cursos e intercâmbios de experiência. A estratégia da APITRA reflete-se no conjunto de atores que formam a governança do projeto, demonstrando que o resultado somente pode ser conseguido a partir das ações conjuntas de todos esses entes.

Esta pesquisa identificou a ausência de ações voltadas para o "pensar estrategicamente" junto às comunidades, o que as fomentaria, através de lições e aprendizados, a interpretar a realidade que se apresenta e identificar onde de fato querem chegar. A pressão pela acumulação do capital impulsiona as organizações a, sempre que possível, aumentarem em porte e receitas (e consequentemente em despesas), no entanto o crescimento deve ser sempre alinhado ao modo de vida e aos esquemas interpretativos presentes em cada local.

\subsubsection{Ação Coletiva}

Os dois projetos apresentaram redução no número de participantes, em torno, de $60 \%$ desde seu início. Quando questionados sobre esta redução, foi dito que muitas famílias decidiram participar sem entender ao certo do que se tratava. Na Comunidade Menino Jesus no Acará, a comunidade relatou desconhecer parte das famílias listadas inicialmente. A pesquisa confirmou o argumento de Olson (1999) que grupos menores tendem a ter maior adesão de seus membros, entre eles pelo fato do 
benefício ser dividido por um número igualmente reduzido de participantes, sendo o benefício recebido significativo a cada membro. Para o autor, grupos grandes são mais susceptíveis a não atingirem seus objetivos, isso se dá por ser o benefício diluído a tal ponto que os custos da participação se excedem aos benefícios alcançados, desestimulando o indivíduo.

A presença de caroneiros, como descrito por Olson (1999) é marcante em todos os projetos, porém se apresenta de variadas formas. Ao analisar a Lógica da Ação coletiva, Mancuso (2013) afirma que os caroneiros preferem que outros indivíduos arquem com as despesas da obtenção do benefício coletivo, para que, desta maneira, possam usufruir das vantagens deles procedentes sem terem que investir seus recursos. Nos casos em questão há na própria comunidade indivíduos dispostos a usufruir dos benefícios sem arcar com seus custos, porém existe também a presença de agentes externos que contribuem para a formação de caroneiros.

A pesquisa demonstrou que há indivíduos externos, ou seja, que não são membros da comunidade, que obtêm benefícios através desse grupo por meio de um comportamento oportunista, tais como políticos com promessas eleitoreiras e interessados unicamente em votos ou empresas prestadoras de serviços preocupadas em ter um número maior de membros no projeto aumentando consequentemente o valor global e o valor pago a elas para a elaboração (um percentual do valor total do projeto).

Em se tratando de regras e sanções, princípios da ação coletiva difundidos por Ostrom (1999), na APITRA o caminhão e o veículo tinham sua utilização norteadas por regras e encontrava-se em fase de elaboração as regras para o entreposto, no entanto é predominante a ausência de regras e a dificuldade na sua construção, como por exemplo os conflitos gerados na Comunidade Menino Jesus para o cumprimento das regras sanitárias na unidade de beneficiamento de farinha. Em nenhum caso estudado houve sanções previstas no caso de descumprimentos de regras.

\subsubsection{Governança}

No mapeamento das relações nos dois projetos o eixo 01 - Poder Público foi aquele onde predominaram as organizações, por sua vez o eixo quatro - Iniciativa Privada não teve nenhuma organização listada em nenhuma das associações. No eixo 02 -Produção prevaleceu a figura do comprador, sendo que somente na APITRA foram mencionados futuros compradores. No eixo 03 - Apoio Técnico foram listados sindicatos, uma universidade, uma empresa prestadora de serviços e órgãos ligados ao sistema " $\mathrm{S}$ ".

No eixo 01, apenas na APITRA foram listadas organizações ligadas às três esferas de poder: municipal, estadual e federal, sendo que ainda assim o relacionamento com a prefeitura ocorre abaixo do esperado pela associação, não configurando uma sintonia entre os agentes públicos. Na Comunidade Menino Jesus apesar do alto número de órgãos estaduais foi identificado que, na maioria dos relacionamentos, o resultado esperado ainda não tinha sido atingido.

No eixo 02 (produção), foram listados por todas as associações somente compradores, não sendo mencionada nenhuma organização ligada à logística (apesar de questionado), demonstrando que na visão das comunidades o eixo de produção ainda é absolutamente vinculado a compra e venda.

No eixo 03 (apoio técnico), destacam-se as capacitações ministradas especialmente pelo SEBRAE (APITRA) e SENAR (Comunidade Menino Jesus), além do papel dos sindicatos e Universidade Federal Rural apoiando os projetos. É válido mencionar que no eixo poder público existem organização como a EMATER, cujo objetivo é prestar assistência técnica às comunidades, por questões metodológicas foram classificadas no eixo 01, porém destacou-se seu papel na assistência técnica dos projetos, sendo listada pelas duas associações. 


\section{CONCLUSÕES}

A pesquisa demonstrou que a estratégia e a forma como a ação coletiva ocorre influenciam diretamente na governança, sendo ela resultado desses fatores. Embora as alianças estabelecidas estejam em sintonia com os objetivos da comunidade, gerando um conjunto de atores com ações individuais, alinhados em busca de resultados específicos voltados para o atingimento de um bem comum, ficou demonstrado que, quando o pensamento estratégico não se faz presente e a ação coletiva é frágil, as relações estabelecidas se configuram numa governança desfavorável ao sucesso dos empreendimentos.

Ficou evidenciado que o elemento educação (aprendizado formal e informal) é um fator fundamental no empoderamento da comunidade. O conhecimento faz com que o cidadão se sinta integrado ao processo, com condições de compreender suas nuances e de alinhar o modelo proposto à realidade local. A preocupação da formação de um núcleo de conhecimento para a comunidade, como ocorre na APITRA, modifica os padrões de parceria dando aos associados maior capacidade de gestão e controle social. A participação efetiva dos atores depende do sentimento de pertencimento que faz com que a comunidade se enxergue como agente de mudança, atuante e disposta a utilizar o projeto como instrumento de alcance de melhor qualidade de vida.

A ação governamental deve ultrapassar o repasse financeiro e o apoio econômico, já que políticas públicas efetivas são aquelas que contribuem não só para a geração de renda, mas também para o desenvolvimento social das comunidades, assegurando a continuidade da ação e a transformação positiva da realidade local, observando suas especificidades. Há diversos elementos intrínsecos e extrínsecos à comunidade que devem ser observados anteriormente e durante a implantação de projetos de desenvolvimento rural. Os arranjos que podem ser constituídos para viabilizar uma estratégia de desenvolvimento dependem de onde aquela comunidade quer chegar, necessitando que ela saiba que caminho que deseja seguir. Cabe ao Estado apoiar a comunidade a atuar neste processo interativo que é a governança, não somente através da formalização de parcerias, como também de ações de capacitação e promoção de conhecimento.

Em se tratando da ação coletiva, o uso adequado do bem comum resultado do projeto depende sim da cooperação e reciprocidade, mas também das regras e sanções e, especialmente, da capacidade que esta comunidade terá de construir e validar essas regras. A presença de caroneiros pode ser diminuída através do elemento comunicação, informando a todos os envolvidos o que é o projeto e, especialmente, os custos individuais necessários para a obtenção do benefício coletivo. O maior entendimento dará aos associados a capacidade de exercer o controle social.

Por fim recomenda-se que projetos de apoio à agricultura familiar analisem anteriormente a ação coletiva da comunidade, os possíveis arranjos que podem se constituir alinhados à estratégia local e às diferentes condições sistêmicas (sociais, econômica, culturais, institucionais e participativas). Tais análises não devem ser feitas com o objetivo de ser excludente, mas sim de potencialização de políticas públicas ao trazer maiores benefícios.

Recomenda-se que novos estudos analisem o resultado da ação coletiva e estratégia na governança em outros projetos ligados ao desenvolvimento rural e que sejam estudadas as relações de governança com agentes da iniciativa privada. Também se recomenda que futuras pesquisas analisem a interferência da governança nos resultados posteriores à implantação de projetos, narrando a sua trajetória após o recebimento do empreendimento e as parcerias construídas a partir daí. 


\section{REFERÊNCIAS}

BALLESTEROS, VHM; ALCOFORADO, I. Tragédia dos Commons e os direitos de propriedade: com Hardin, além de Hardin. In: ENCONTRO DA SOCIEDADE BRASILEIRA DE ECONOMIA ECOLÓGICA, 8, 2009, Cuiabá. Anais [...]. Cuiabá, MT: ECOECO, 2009

BUENO, N.P. Lógica da ação coletiva, instituições e crescimento econômico: uma resenha temática sobre a nova economia institucional. Revista Economia, Curitiba, PR, v. 5, n. 2, p. 361-420, 2004.

COCHIA, C. B; MACHADO-DA-SILVA, C. L. Ambiente, Interpretação e Estratégia em Organizações Paranaenses dos Setores de Vestuário e Alimentos, RAC - Revista de

Administração Contemporânea, Maringá, PR, v. 8, p. 11- 35, 2004. Edição especial

GIL, A. C. Métodos e técnicas de pesquisa social. São Paulo: Atlas, 1999.

GONÇALVES, A.F. O conceito de governança. In: CONGRESSO NACINAL DO CONSELHO NACIONAL DE PESQUISA E PÓS- GRADUAÇÃO EM DIREITO, 14. 2005, Fortaleza. Anais [...]. Fortaleza: CONPENDI, 2005.

HARDIN, G. The tragedy of the Commons. Science, v. 162, n.3859, p. 1243-1248, dec. 1968.

JUSTEN, G. S. et al. Estruturas de governança em sistemas produtivos locais: o caso do Projeto Reca. In: ENCONTRO INTERNACIONAL SOBRE GESTÃO EMPRESARIAL E AMBIENTAL, 16, 2014, São Paulo. Anais [...]. São Paulo: ENGEMA, 2014.

KISSLER, L; HEIDEMANN, F. G. Governança pública: novo modelo regulatório para as relações entre Estado, mercado e sociedade? Revista de Administração Pública, Rio de Janeiro, v. 40, n. 3 , p. 479-499, 2006

LAURIOLA, V. Elinor Ostrom: um Nobel heterodoxo e rosa-verde. Sinal de esperança? Boletim da Sociedade Brasileira de Economia Ecológica, Brasília DF, n. 21, p. 3-8, 2009.

MACHADO-DA-SILVA, C. L.; FONSECA, V. S da; FERNANDES, B. H. Mudança e estratégia nas organizações: perspectivas cognitiva e institucional. In: VIEIRA, Marcelo Milano Falcão; BARBOSA, Lúcia Maria (orgs.). Administração contemporânea: perspectivas estratégicas. São Paulo: Atlas, 1999. p. 102-118.

MANCUSO, Wagner Pralon. Construindo leis: os construtores e as concessões de serviços. Lua Nova, São Paulo, v. 58, p. 61-87, 2003.

MARCONI, M. A.; LAKATOS, E. M. Fundamentos de metodologia científica. 7.ed. São Paulo: Atlas, 2010. 
NAVARRO, Z. Desenvolvimento rural no Brasil: os limites do passado e os caminhos do futuro. Revista Estudos Avançados, São Paulo, v.16, n. 44, 2001

OLSON, M. A lógica da ação coletiva: os benefícios públicos e uma teoria dos grupos sociais. São Paulo: Edusp, 1999.

OSTROM, E. Governing the commons: the evolution of institutions for collective action. Cambridge: Cambridge University Press, 1990.

OSTROM, E. Coping with tragedies of the commons. Annual review of political science, v. 2, n. 1, p. 493-535, 1999.

PARÁ RURAL- Programa de Redução da Pobreza e Gestão dos Recursos Naturais do Pará. v.1. Concepção e Implementação do Programa, jan. 2014.

PEREIRA, F. M. A evolução da teoria institucional nos estudos organizacionais: um campo de pesquisa a ser explorado. Revista Organizações em Contexto-online, São Bernardo do Campo, SP, v. 8, n. 16, p. 275-295, 2012.

RAUPP, F. M.; BEUREN, I. M. Metodologia da pesquisa aplicável às ciências sociais. In: BEUREN, Ilse Maria (org.). Como elaborar trabalhos monográficos em contabilidade: teoria e prática. São Paulo: Atlas, 2003

SABOURIN, E. Manejo dos recursos comuns e reciprocidade: os aportes de Elinor Ostrom ao debate. Sustentabilidade em Debate, Brasília, DF, v. 1, n. 2, p. 143-158, 2010

SANTOS, M. C. Governabilidade, governança e democracia: criação de capacidade governativa e relações executivo legislativo no Brasil pós-constituinte. Dados, Rio de Janeiro, v. 40, n. 3, 1997

SILVA, E. L. MENEZES, E. M. Metodologia da pesquisa e elaboração de dissertação. Laboratório de Ensino a Distância da UFSC. 2000.

STOKER, G. Governance as theory: five propositions. International Social Sciences Journal, 155, p. 17-28. 1998

TAKAHASHI, A. W.; MACHADO-DA-SILVA, C. L. Ambiente, interpretação e estratégia: estudo comparativo de casos em duas organizações escolares. In: ENCONTRO ANUAL DA ASSOCIAÇÃO NACIONAL DOS PRO-GRADUAÇÃO EM ADMINISTRAÇÃO, 26, 2002, Salvador. Anais [...]. Salvador, BA: ANPAD, 2002.

WORLD BANK. Governance and development. Washington, EUA: Oxford University Press, 1992. 


\section{Dados dos autores:}

\section{Brenda Cordovil Corrêa dos Santos}

ORCID: https://orcid.org/0000-0002-5491-1446

Mestrado em Administração pela Universidade da Amazônia. Professora na Universidade Federal Rural da Amazônia (UFRA). Belém, Pará, Brasil. E-mail: brendacordovil@ yahoo.com.br.

\section{Mário Miguel Amin Garcia Herreros}

ORCID: https://orcid.org/0000-0003-1166-5350

Doutor em Agricultural Economics pela Universidade da Florida (USA). Professor do Programa de Pós-Graduação em Administração (PPAD) e em Desenvolvimento e Meio Ambiente Urbano da Universidade da Amazônia (UNAMA) e Professor do Programa de Mestrado em Gestão Pública do Núcleo de Altos Estudos Amazônicos da Universidade Federal do Pará. Belém, Pará, Brasil. E-mail: marioamin@gmail.com.

\section{AGRADECIMENTO:}

\section{In memoriam ao prof. Mário Miguel Amin Garcia Herreros}

Professor Dr. Mário Amin foi fonte de inspiração para aqueles que o conheceram. Com ele aprendi que amar a docência nos leva a fazer a diferença e escrever a história de um mundo melhor. Aprendi também que o bom professor sonha junto, acredita e incentiva. Ao longo de sua vida, o professor Amin plantou sementes de saber que quebraram barreiras e ultrapassaram fronteiras. Viajaram pela Colômbia, Estados Unidos, floresceram na Amazônia, lugar que ele tanto amava, e alcançaram o mundo. Os frutos do saber se multiplicam em seu legado, em suas pesquisas, em seus alunos e nos alunos dos alunos, um verdadeiro ciclo que não tem limites, transcende o tempo e o espaço, se perpetua. Tudo que é verdadeiro não morre. Nada, nem a COVID vai apagar. Gratidão eterna, meu querido professor!

\section{Brenda Cordovil Corrêa dos Santos}

